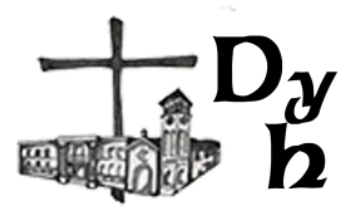

Nuevo estudio para la caracterización y el trabajo con jóvenes universitarios sobre indiferencia religiosa Enma Carmen Leiva Sánchez, Ángel Patricio Valverde Gavilanes, Blanca Azucena Oñate Sánchez, René Alonso Ayala Guamangate Dios y el hombre, vol. 5, n. 1, e078, 2021

ISSN 2618-2858 - https://doi.org/10.24215/26182858e078

https://revistas.unlp.edu.ar/DyH/index

Cátedra libre de pensamiento cristiano - UNLP

Seminario Mayor San José

La Plata, Buenos Aires, Argentina

\title{
NUEVO ESTUDIO PARA LA CARACTERIZACIÓN Y EL TRABAJO CON JÓVENES UNIVERSITARIOS SOBRE INDIFERENCIA RELIGIOSA
}

A New Study for the Characterization and Work with Young University People about Religious Indifference

\section{Enma Carmen Leiva Sánchez | Ángel Patricio Valverde Gavilanes | Blanca Azucena Oñate Sánchez | René Alonso Ayala Guamangate}

eleiva@pucesa.edu.ec | pvalverde@pucesa.edu.ec | aonate@pucesa.edu.ec I rayala@pucesa.edu.ec Pontificia Universidad Católica del Ecuador - Ambato - Ecuador

\section{Resumen}

Considerando que los principios morales de la religión son normas y preceptos que perfeccionan al ser humano con las acciones buenas que realiza, esta investigación se le considera importante para grupos de laicos, religiosos, estatales y de otros credos. El objetivo es identificar las causas y consecuencias de la indiferencia hacia la religión, el vacío de identidad religiosa y la carestía de valores morales y religiosos. Las mismas se analizan desde una perspectiva cuantitativa que enriquece el trabajo cualitativo de este artículo. El resultado de este estudio es una caracterización parcial del joven universitario actual que se evidencia las principales causas de la indiferencia religiosa, tales como: ejemplo negativo de los líderes religiosos, descomposición familiar e influencia del internet.

Palabras clave: líderes religiosos; principios éticos; valores morales.

\section{Abstract}

Taking into consideration that the religious moral principles are norms and precepts that shape the human being with the good actions that he takes, this research is considered important for groups of laities, religious, state, and other faiths. The objective is to identify the causes and consequences of indifference towards religion, the emptiness of religious identity and the lack of moral and religious values. They are analyzed from a quantitative perspective that enriches the qualitative work of this article. The result of this study is a partial characterization of the youth university student of today that shows the main causes of religious indifference, such as: negative example of religious leaders, family decomposition and influence of the internet.

Keywords: religious leaders; ethical principles; moral values.

Recibido: 02/02/2021

Aceptado: 20/05/2021

Publicado: 12/07/2021 


\section{Introducción}

En la última década se aprecia un incremento de la indiferencia religiosa (en adelante, I.R.) que ha conllevado a buscar métodos de medición y evaluación no empleados hasta inicios del siglo XXI. En este sentido, el estudio que se presenta se enfoca en una nueva perspectiva por ser un tema de interés en todo ámbito, pues afecta el estilo de vida en la sociedad, debido a que parte de la formación académica. Existe, además, escasa participación de los jóvenes en las actividades religiosas, que han sido observadas en las aulas universitarias, cuando no participan de novenas, retiros espirituales, convivencias, eucaristías, entre otros.

Ciertos jóvenes buscan a Dios desde su naturaleza espiritual por su propia convicción; pero también algunos de ellos viven sin ninguna religión, ya sea porque han reconocido, desde sus reflexiones, la no existencia de Dios, porque han optado por un modo de vivir que deje de lado sin afirmarla o negarla la hipótesis "Dios", o porque simplemente han nacido en un hogar y en un ambiente donde no había la menor huella de Dios, según Pascual, F. (2014).

La sociedad actual vive sin Dios porque es fruto de la carencia de valores trascendentales -entendiéndose como sociedad al conjunto de personas que se relacionan entre sí, de acuerdo a unas determinadas reglas de organización que comparte una misma cultura o civilización en un espacio o tiempos determinados (RAE)-, con una forma peculiar de increencia, donde ni siquiera se plantea la cuestión de la existencia de Dios, porque, al parecer, no siente inquietud religiosa alguna y no percibe el motivo de preocuparse por el hecho religioso; actitud que podemos observar en los jóvenes de esta época y que se ha extendido en todos los ámbitos y vivencias del ser humano (Concilio Vaticano II, 1995, 19,2).

Otra forma de I.R. en la actualidad se encuentra en el agnosticismo, que se define como la actitud filosófica que declara inaccesible al entendimiento humano todo conocimiento de lo divino y de lo que trasciende la experiencia (RAE, 2014); esta corriente filosófica influye en los estudiantes universitarios en un estilo de vida que deja secuelas de vaciedad espiritual. 
En la presente investigación se asume la visión de la PUCESA ${ }^{1}$ que se inspira en los principios cristianos, el respeto a la dignidad y derechos de la persona humana y a sus valores trascendentes, así como a su misión de responsabilidad ante Dios, impartiendo una formación integral del ser humano, con valores cristianos y éticos, que busca mejorar el conocimiento sobre la juventud y su relación con lo trascendente. (Peña, s.f.)

\section{Indiferencia Religiosa}

Ciertos jóvenes viven una época en que los avances tecnológicos no les permiten encontrar espacios de reflexión con Dios, consigo mismos y con los demás. Por consiguiente, la investigación sobre la I.R. de los jóvenes universitarios del cantón Ambato no admite conocer su actitud frente a la espiritualidad.

En las Universidades Técnica de Ambato, Uniandes, Indoamérica y Pontificia Universidad Católica del Ecuador Sede Ambato, se percibe un alto nivel de I.R. en algunos jóvenes cuya manifestación es alejarse del hecho religioso.

La I.R., cada vez más, se manifiesta en las personas y en especial en los jóvenes de todo el mundo; por ello, se cree pertinente y necesario complementar la investigación con opiniones de autores que en los contextos europeo y latinoamericano han indagado sobre esta temática, lo cual permite tener una visión más amplia sobre las causas y las consecuencias del fenómeno indiferencia religiosa en la juventud universitaria.

Velasco (1998), manifiesta que la I.R. se debe a: a) la indiferencia a la propia religión, b) la indiferencia religiosa propiamente dicha, c) factores como: el cambio cultural que atraviesan las sociedades occidentales; la civilización científica y técnica, fruto de la relación del hombre moderno con la naturaleza y el mundo; la secularización de la sociedad, además, del escándalo del mal, que pone en crisis la concepción de un Dios absoluto de bondad.

\footnotetext{
${ }^{1}$ Nota del Editor: los autores se refieren a la Pontificia Universidad Católica del Ecuador, sede Ambato.
} 
Por consiguiente, las consecuencias están a la vista. Frente a la modernidad que abre espacios sensibles a lo humano, hoy más que nunca la tecnología tiene repercusiones para la humanidad; sin embargo, la sociedad secularizada también es una oportunidad para la fe y esto obliga a hacer opciones personales consigo mismo y con Dios.

De lo anteriormente mencionado, la I.R. ha marcado grandes cambios sobre la idea de Dios y su importancia para el ser humano, independientemente del credo que se profese. Por lo tanto, es necesario recalcar que frente a la I.R. es sustancial tener en cuenta aspectos como educar en valores, reactivar la actitud crítica, anunciar con credibilidad el centro de la fe (Ortiz. A, 1993, pág. 115-118).

En efecto, los indiferentes en materia religiosa, de una manera estricta, son aquellas personas que carecen de interés de saber si Dios existe o no, porque aún en el supuesto de que existiera, no sería para ellos un valor digno de tener en cuenta. Según este contenido ideológico, en esta época posmoderna, la indiferencia en el aspecto religioso es un vacío de Dios en el ser humano que vive serenamente inmerso en lo superfluo sin el cuestionamiento sobre su existencia (Serrano, J. P. G., González-Carvajal, L., \& Velasco, J. M., 2011, pág. 11-13).

Así, el ser humano vive una superficialidad que no contempla la existencia de Dios, además, de una religiosidad a la carta como una expresión individualista, la misma que ha dado origen a nuevas formas de I.R. como el peso de subjetivismo y de la afectividad, cuyas formas no permiten la búsqueda del verdadero sentido de la vivencia religiosa.

En estos últimos años, la I.R. se ha elevado notablemente. Es así que una mayoría se declara católica no practicante, seguida por una minoría que no pertenece a ninguna religión y un reducido número de personas que comulga con religiones distintas. Según, Campos (2013), las nuevas generaciones se desarrollan de manera escéptica y vacía de espiritualidad.

Tales investigaciones realizadas por estos autores concuerdan con la percepción del vacío de Dios en la juventud, al referirse a las formas de ateísmo y en especial en aquellos que ni siquiera plantean la cuestión de la existencia de Dios porque, al parecer, no sienten inquietud religiosa alguna y no perciben el motivo de preocuparse por el hecho religioso (Concilio Vaticano II, 1995). 
Es evidente, entonces, que en la investigación se plantee el siguiente problema: ¿Cómo dinamizar el proceso de formación espiritual en la juventud universitaria del cantón Ambato?, cuya finalidad es identificar las causas y consecuencias de la I.R. en la juventud universitaria del cantón Ambato, Ecuador.

\section{Métodos}

En el desarrollo del proceso investigativo se utiliza el método teórico de Análisis-Síntesis en la sistematización del estado de arte en base a los diferentes aportes teóricos de los autores sobre la I.R. De igual forma, el método ExploratorioExplicativo, el cual contribuye a la obtención de datos reales empíricos que describen la situación actual de la I.R. en la juventud universitaria.

El universo de estudio en esta investigación son cuatro universidades, para lo cual se contó con la autorización de las respectivas autoridades: la Universidad Técnica de Ambato, la Pontificia Universidad Católica del Ecuador Sede Ambato, la Universidad Regional Autónoma de Los Andes y la Universidad Tecnológica Indoamérica. La aplicación del método a los 542 encuestados universitarios de niveles intermedios se realiza con profundidad en determinados ámbitos.

Se aplica la técnica de la encuesta con su instrumento (cuestionario, publicado en el anexo al final del artículo) formado de 13 preguntas, las mismas que fueron socializadas y validadas mediante observaciones y sugerencias respectivas por personas vinculadas con el trabajo religioso, destacándose 5 sacerdotes, 5 teólogos y 3 pastores; adicionalmente, 4 académicos universitarios, quienes con sus valiosas sugerencias apoyaron el presente estudio. Además, se utiliza la entrevista para la recopilación de la información respaldada en videos y fotografías, anexada como evidencias en la página web del Departamento de Pastoral de la Pontificia Universidad Católica del Ecuador Sede Ambato. El empleo de varias técnicas para la obtención de información permite enriquecer el estudio y comparar el análisis de los implicados con diferentes formas de investigación, considerándose la combinación de la metodología de investigación una nueva forma de enriquecimiento y rigor científico a partir de criterios encontrados según fundamentos de la dialéctica, pues sus resultados han generado nuevas perspectivas para enfrentar nuevas investigaciones sobre el tema abordado. 


\section{Resultados y discusión}

En este acápite se desarrolla el análisis e interpretación de resultados a partir de las técnicas empleadas en la investigación, las cuales se abordan a continuación.

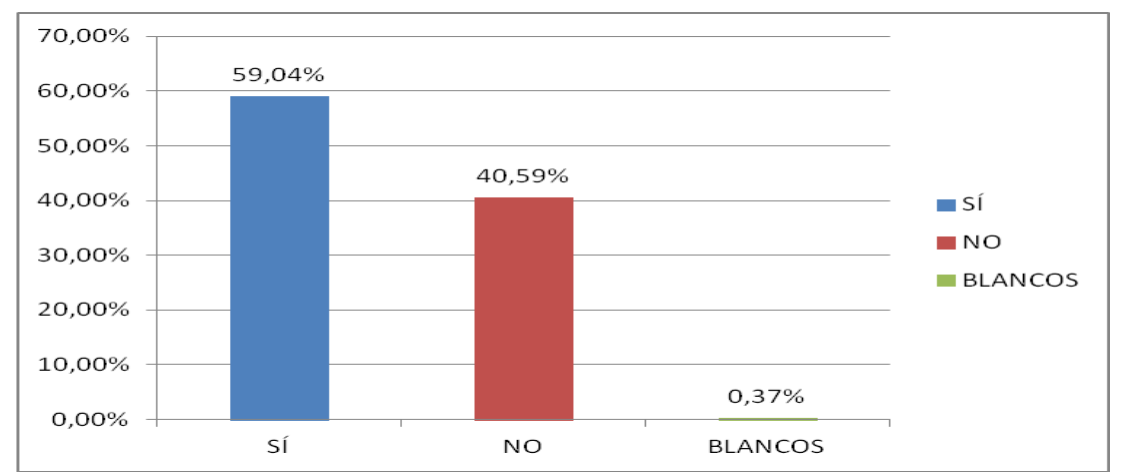

Gráfico 1: Cuestionamiento de la existencia de Dios

Fuente: elaboración propia

En el gráfico 1 se observa que el 59,04\% cuestiona la existencia de Dios; frente a un 40,59\% que no lo hace. El cuestionamiento sobre la existencia de Dios, presenta un considerable porcentaje, el mismo que se podría atribuir según el criterio de la investigación a la influencia familiar y sus respectivas ideologías religiosas. En un menor porcentaje no se cuestiona la existencia de Dios, que respondería a un cierto tipo de I.R., que se acentúa por el mundo convulso ${ }^{2}$ que vive la sociedad (violencia, atentados, terrorismo, entre otros), en el cual la religión ha sido tomada como bandera de manera errónea por sectas religiosas, mormones, testigos de jehová, adventistas, entre otros.

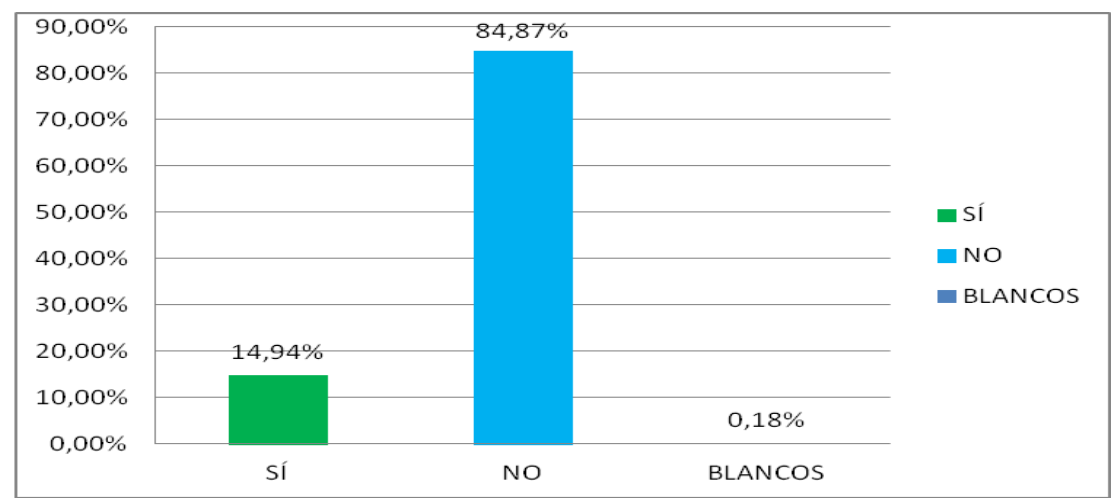

Gráfico 2: Necesidad de profesar una religión para creer en Dios

Fuente: elaboración propia

\footnotetext{
${ }^{2}$ Tipo de calambre, espasmo o síncope que afecta a la humanidad.
} 
En el Gráfico 2, se observa que el 14,94\% de los estudiantes universitarios manifiesta que sí es necesario profesar una religión para creer en Dios; frente a un $84,87 \%$ que revela que no es necesario ejercer un culto para creer en Dios.

Rincón, A (2018) manifiesta que:

La religión o las religiones han consolidado desde siempre, la cultura en la que se encuentra inserto el hombre. Ella, desde su origen, está en la búsqueda de un Dios protector que es necesidad de muchos hombres y de la humanidad para que quite los sufrimientos de los seres humanos, que confían en él por medio de la fe, que han tratado de buscar su significado a través de la teología y la filosofía.

Desde esta perspectiva, es vital tener en cuenta que la religión debería ser abordada desde la familia y la escuela para ser vivida y para que sea la protagonista en la consolidación de los valores espirituales, sociales, familiares y personales.

Por consiguiente, es necesario profesar una religión que forme parte de la educación integral a la que todo ser humano tiene derecho, puesto que ello significa el reconocimiento de sí mismo y de ser persona; que desarrolle un sistema ético y moral con unos valores, que ayudan a no caer en el relativismo moral que están viviendo algunas sociedades y culturas tomadas por el consumismo, la mercantilización de la vida, el facilismo y la corrupción. Esto implica compromiso, responsabilidad y adhesión a la religión que profesa.

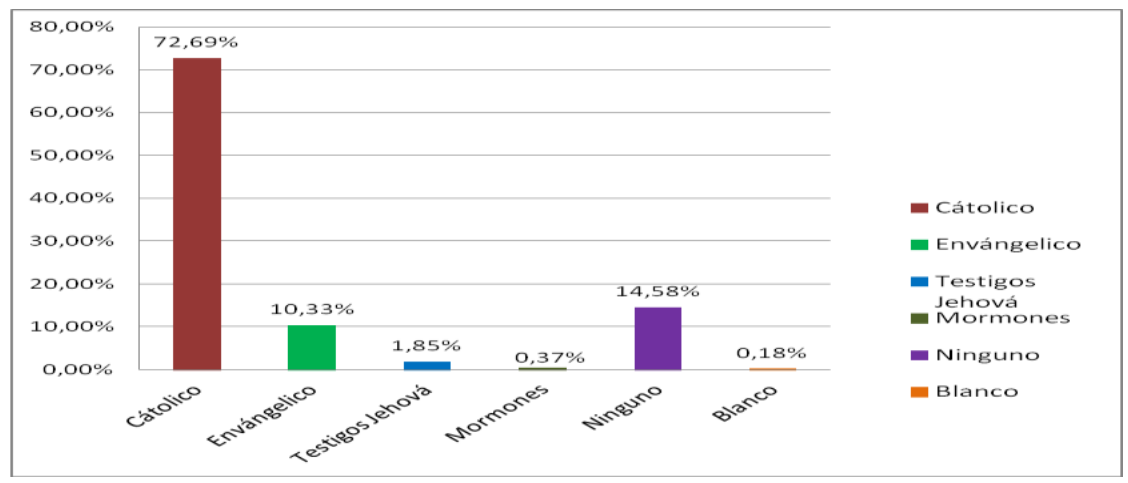

Gráfico 3: ¿Con qué Religión se identifica?

Fuente: elaboración propia 
En el gráfico 3, se observa que el 72,69\% de estudiantes universitarios se identifica con la religión católica; el 10,33\% con la religión evangélica; el 1,85\% como Testigos de Jehová; el $0,37 \%$ se identifica como mormones; mientras que el $14,58 \%$ no se identifica con ninguna religión. En este sentido, el porcentaje mayor se identifica con la religión católica debido a que Ecuador es un país de tradiciones religiosas católicas marcadas en la religiosidad popular, seguido de un porcentaje que no se identifica con ninguna religión debido a que vivimos en una sociedad secularizada. De la misma manera, se destaca que la religión que domina en Ecuador se centra en la educación de valores y en sentimientos de sana convivencia familiar y social, por ello existiría la preocupación de la desviación de los jóvenes a otros tipos de comportamientos diferentes a los que predica la religión católica. De igual forma, están presentes las religiones evangélicas, testigos de Jehová y mormones, con un porcentaje mínimo, amparadas en la Constitución ${ }^{3}$, que garantiza la libertad de culto; estos hechos confunden a los seguidores de las religiones cuyo resultado es el abandono de sus credos y pasan a engrosar el porcentaje de jóvenes que no profesan ninguna religión.

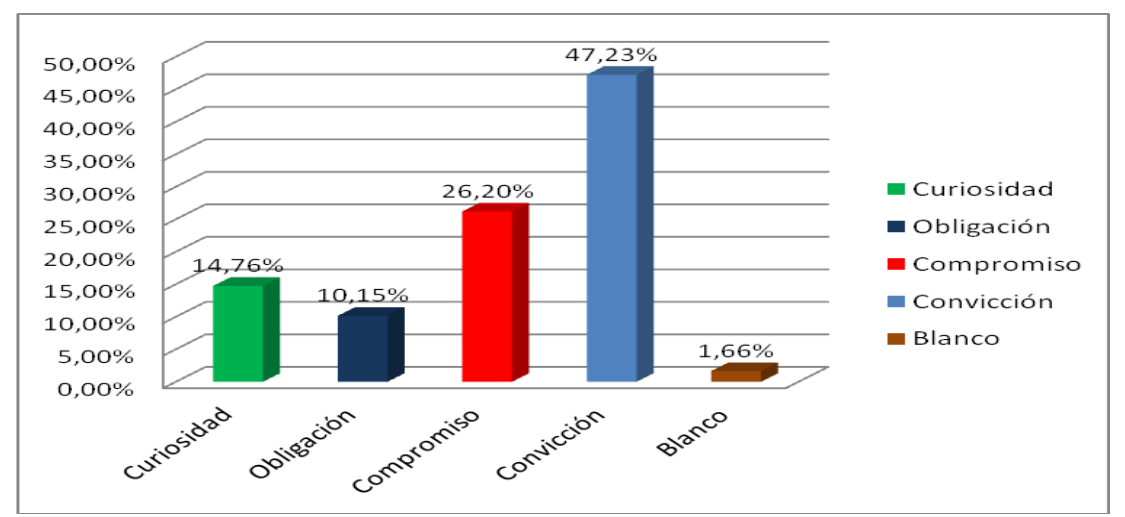

Gráfico 4: Motivaciones que le llevan a participar en las actividades religiosas Fuente: elaboración propia

\footnotetext{
${ }^{3}$ Constitución Política del Ecuador Art. 66 numeral 8. El derecho a practicar, conservar, cambiar, profesar en público o en privado, su religión o sus creencias, y a difundirlas individual o colectivamente, con las restricciones que impone el respeto a los derechos. El Estado protegerá la práctica religiosa voluntaria, así como la expresión de quienes no profesan religión alguna, y favorecerá un ambiente de pluralidad y tolerancia.
} 
Como se observa en el gráfico 4 , el 14,76\% de los jóvenes universitarios manifiesta que asisten por curiosidad a actividades religiosas; el 10,15\% participa por obligación; mientras que el 26,20\% asiste por compromiso; el 47,23\% por convicción y un 1,66\% no responden al interrogante planteado.

La mayoría de jóvenes participa por convicción en las actividades religiosas, que representa una juventud convencida de sus creencias y valores religiosos; en segundo lugar, se ubica el compromiso de jóvenes que responden de manera consciente a cumplir con sus actividades religiosas; en tercer lugar, se tiene la curiosidad y en el cuarto lugar la obligación. Estas motivaciones permiten tener una visión clara del comportamiento de la juventud sobre su participación en los actos religiosos.

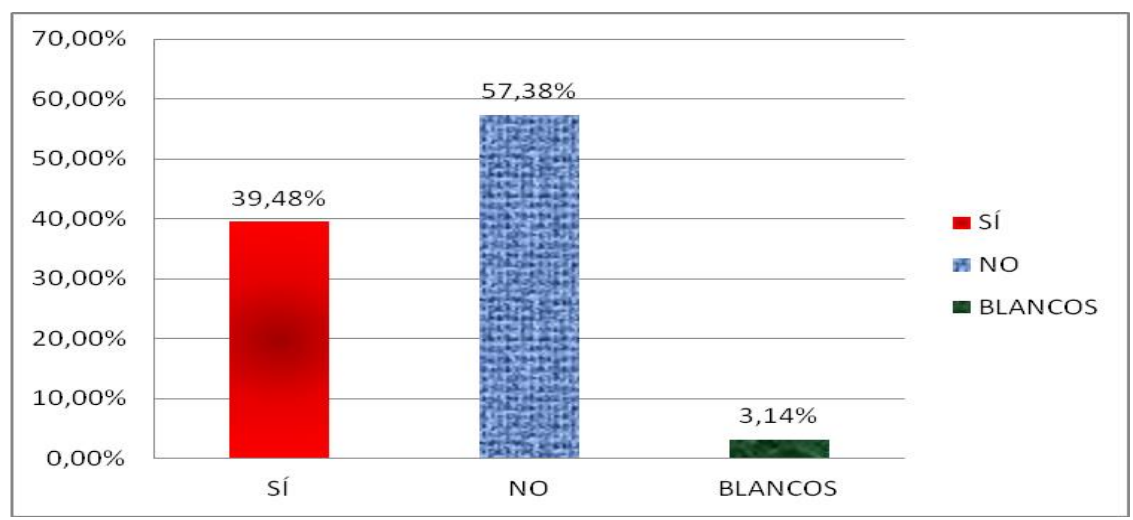

Gráfico 5: ¿Han pasado de moda los valores morales de la religión?

Fuente: elaboración propia

En el gráfico 5, se observa que el 39,48\% de estudiantes universitarios piensa que los principios morales de la religión sí han pasado de moda frente a un 57,38\% que considera que los principios morales de la religión no han pasado de moda.

Se analiza que los jóvenes universitarios en un porcentaje mayor creen que los principios morales de la religión aún están vigentes, ya que en nuestra sociedad como un todo prevalece el valor de la religión, seguido de un porcentaje considerable que opinan que los principios y valores han pasado de moda por la influencia de un mundo materializado. 


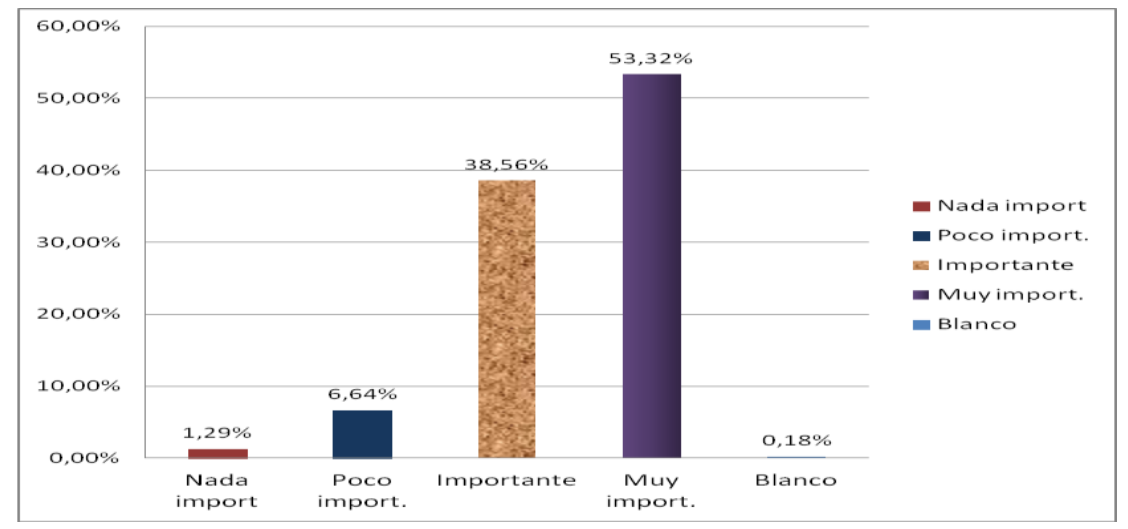

Gráfico 6: El núcleo familiar y la educación espiritual

Fuente: elaboración propia

Como se observa en el gráfico 6 , el 1,29\% de estudiantes universitarios manifiesta que no es importante en el núcleo familiar una educación espiritual; mientras que el 6,64\% manifiesta que es poco importante; el 38,56\% revelan que es importante en el núcleo familiar la educación espiritual y el 53,32\% consideran que es muy importante la educación espiritual en la familia.

Como muestra el gráfico, existe un porcentaje mayor que considera que es muy importante una educación espiritual en la familia debido a una educación en principios y valores religiosos que todavía se imparten en sus hogares, ya sea por tradición o compromiso. Mientras que otros grupos de estudiantes, consideran importante, poco importante, nada importante la educación espiritual en la familia, conforme responda a sus motivaciones.

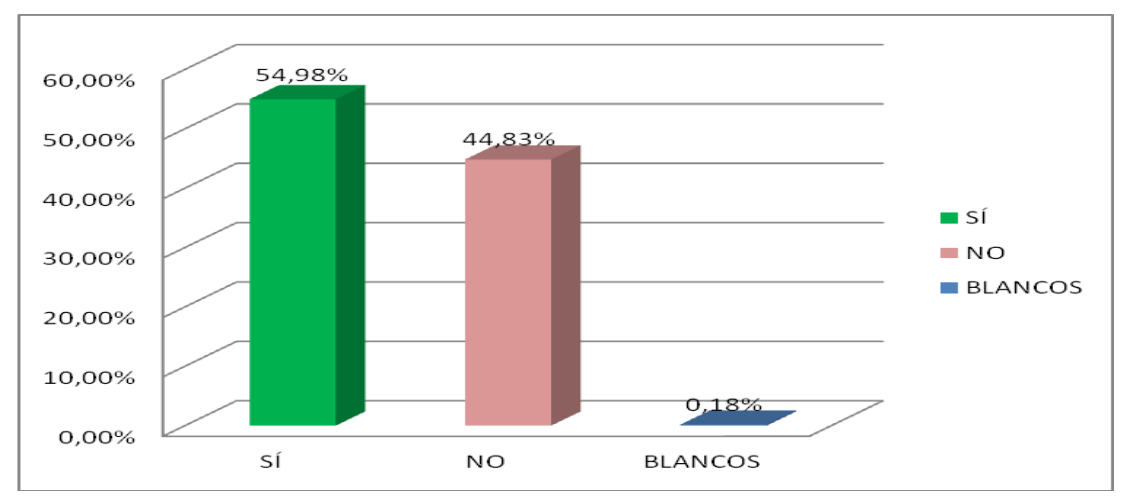

Gráfico 7: Descomposición familiar a causa de la carencia de valores religiosos Fuente: elaboración propia 
En el gráfico 7, se observa que el 54,98\% de estudiantes universitarios del cantón Ambato manifiesta que la descomposición familiar es fruto de la carencia de valores religiosos; mientras que un 44,83\%, no considera que la descomposición familiar sea producto de la carencia de valores religiosos.

El porcentaje alto es consecuencia de la carencia de valores religiosos, debido a que en la actualidad la descomposición familiar se debe a la falta de compromiso en formar una familia, cuyo origen se encuentra en la unión libre, matrimonios mixtos, divorcios y la migración a otros países que ahonda más esta problemática. Seguido de un considerable porcentaje que estima que la descomposición familiar no es resultado de la carencia de valores religiosos por vivir en una sociedad secularizada donde prima el materialismo y el consumismo.

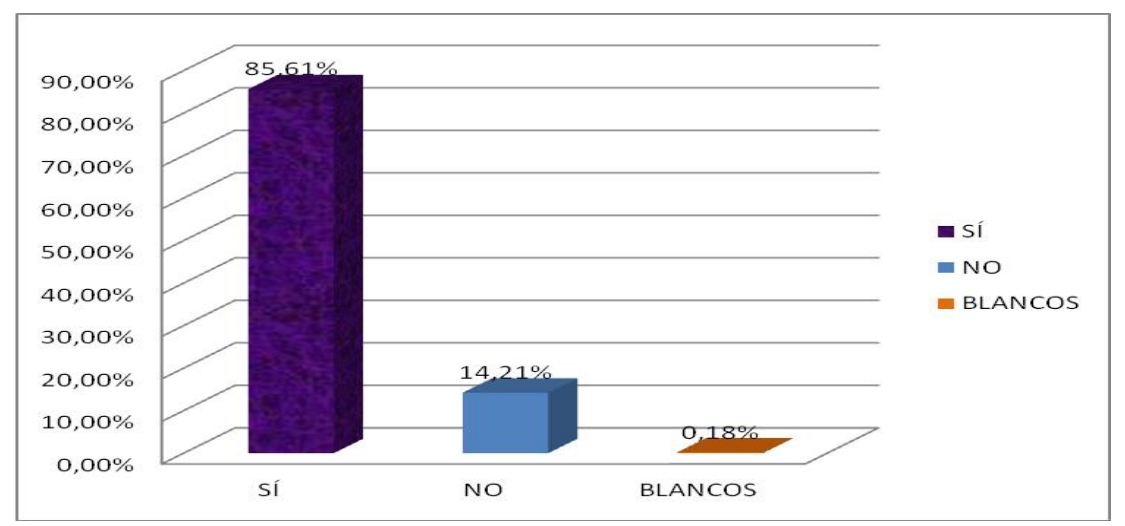

Gráfico 8: El materialismo y la identidad religiosa de los jóvenes universitarios Fuente: elaboración propia

Como se observa en el gráfico 8 , el $85,61 \%$ de estudiantes universitarios creen que el materialismo afecta a la identidad religiosa de las personas, frente a un $14,21 \%$ que considera que el materialismo no afecta a la identidad religiosa.

En efecto, el materialismo es una corriente que crece en el mundo actual, que afecta de manera directa a la identidad religiosa de los universitarios, los mismos que se dejan llevar por todas aquellas vicisitudes que les ofrece el mundo: fama, poder, dinero entre otros, cuya consecuencia se refleja en el alejamiento e indiferencia a todo aquello que viene de Dios. 
De esta manera, los jóvenes encuentran en el materialismo, la única realidad en el mundo $y$, desde esta perspectiva, intentan explicar todo aquello que sucede a nuestro alrededor, como actividades de la materia, cuyo resultado es la negación de Dios que afecta la religiosidad y dañan la personalidad.

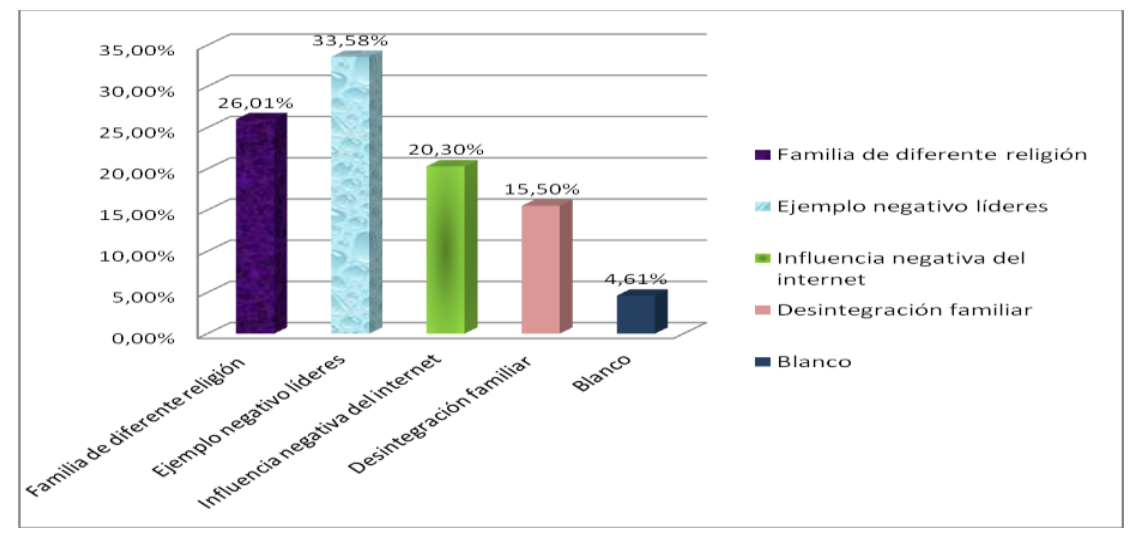

Gráfico 9: El joven universitario y la indiferencia hacia la religión Fuente: elaboración propia

En el gráfico 9, se observa que el 26,01\% de los estudiantes universitarios manifiesta que hay indiferencia hacia la religión por las familias de diferente religión; mientras que el 33,58\% revela que hay indiferencia por el ejemplo negativo de líderes; el 20,30\% manifiesta que hay indiferencia por la influencia negativa del internet; el 15,50\% muestra que hay indiferencia por la desintegración familiar y un $4,61 \%$ no responde al interrogante planteado.

En primer lugar, el joven universitario atribuye la I.R. al ejemplo negativo de los líderes religiosos, que se han dejado influenciar por todas las cosas atractivas que ofrece el mundo. Los jóvenes ven en los líderes religiosos un ejemplo a seguir $y$, si observan actitudes contrarias a su misión, simplemente se alejan y adquieren una actitud de indiferencia a todo aquello que se relaciona con la religión.

En segundo lugar, se encuentran las familias de diferente religión, a las que pertenecen personas que, por confusión de fe, y por diversos cuestionamientos crecen sin identidad religiosa, dándose como resultado la I.R. En tercer lugar, la influencia negativa del internet, que en la juventud universitaria es marcante, porque absorbe su identidad, ofreciéndole al joven una vida superficial escasa en valores humanos y religiosos, los cuales demuestran un estilo de vida diferente; en 
cuarto lugar, se ubica la desintegración familiar que afecta la estabilidad de las familias, debido a que sus miembros pertenecen a distintas denominaciones religiosas, lo que trae como consecuencia ruptura y separación en las familias.

\section{Entrevistas en profundidad}

En la presente investigación se entrevistó a dos estudiantes universitarios pertenecientes a la Universidad Técnica de Ambato y a la Pontifica Universidad Católica del Ecuador Sede Ambato, cuya entrevista permitió que los jóvenes se expresen con toda libertad sobre la temática de la investigación.

El joven D.N., estudiante de la Universidad Técnica de Ambato, menciona que la I.R. se debe al mal testimonio de los líderes religiosos, cuyos comportamientos no apegados a su misión provocan en los jóvenes un rechazo a sus creencias, puesto que los errores cometidos como seres humanos han lastimado a los jóvenes y aunque no se debe juzgar el actuar de cada uno de ellos, precisa que los jóvenes deberían mantenerse en la fe sin abandonar sus credos.

De igual forma, comenta que la I.R. también es fruto de la descomposición de la familia, la cual debe ser reformada como base primordial en la sociedad. Como mensaje final, el joven añade: "es necesario profesar una fe en Dios para poder tener un mejor convivir social y familiar".

En la segunda entrevista el joven V.V., estudiante de la Pontificia Universidad Católica del Ecuador sede Ambato, al referirse a la temática de la investigación manifiesta que el libertinaje es uno de los factores que desorienta a la juventud actual provocando inseguridad emocional, espiritual y afectiva, acarreando como consecuencia una vida sin Dios. Otro aspecto que señala es que los padres tienen vergüenza de profesar una religión haciendo que esta actitud se transmita de generación en generación. $Y$, como mensaje final, el joven añade que hay una carencia de formación en valores cristianos ya "que todo viene desde el hogar".

La juventud universitaria en la actualidad se caracteriza por una profunda indiferencia a todo lo relacionado con las religiones y por consiguiente con Dios. De acuerdo a los resultados se puede caracterizar al joven universitario carente de sensibilidad religiosa, absorbido por la sociedad de consumo a través de los medios de comunicación que constantemente influyen en su actuar. 
El joven Universitario expresa, como causa de la indiferencia religiosa, el mal ejemplo de los líderes religiosos ${ }^{4}$. Como consecuencia, ese mal ejemplo influye notablemente en aquellos jóvenes que ven en estos líderes religiosos un modelo de vida a seguir; cuando observan acciones contrarias a su misión, abandonan su religión y adoptan una postura indiferente. Otra causa que los jóvenes señalan sobre la indiferencia religiosa es que algunas familias no tienen muy bien definido su credo religioso $y$, como consecuencia, crean una profunda confusión de identidad religiosa cuya salida se da a través del abandono de sus credos y adoptan una indiferencia que se traduce en un quemeimportismo hacia Dios. Por último, atribuyen al internet como una influencia negativa porque crea en el joven una falsa identidad a través del consumismo cuyo resultado es el abandono de lo espiritual.

\section{Conclusiones}

El estado del arte consolida el estudio de la perspectiva sobre la indiferencia religiosa en los jóvenes universitarios del Cantón Ambato, fundamentándose la temática estudiada en el aporte de varios autores que cuestionan, describen y afirman la I.R. en la sociedad, que establece la viabilidad del proyecto mediante nuevas perspectivas de investigación desarrolladas por los autores de este estudio.

Con la metodología utilizada, se obtiene información precisa y oportuna de las causas y consecuencias del presente proyecto para esclarecer la I.R. en la juventud universitaria del cantón Ambato. Dichos resultados permitirán análisis y reflexiones en la enseñanza religiosa en las universidades ecuatorianas.

Se adquiere el perfil del joven universitario que manifiesta un alto nivel de indiferencia hacia la religión, que considera que no es necesario profesar una doctrina para creer en Dios; que reconoce que la descomposición familiar es fruto de la carencia de valores religiosos, mostrándose indiferente a todo aquello que viene de la Religión, que identifica al materialismo como una corriente contradictoria a la fe y que el mal ejemplo de los líderes religiosos -como

\footnotetext{
4 Aquellos que llevan un cargo de importancia dentro de la organización religiosa, consiguiendo que los seguidores de dicha religión se inspiren y los sigan. Entre ellos tenemos Sacerdotes, Ancianos, Pastores, Rabinos entre otros.
} 
conductas antiéticas, mentira, vida ostentosa, fraude, corrupción, injusticia- crean un ambiente de inestabilidad y confusión en los jóvenes, cuyo resultado es la I.R.

Hasta el momento, esta investigación de la I.R. en la juventud universitaria del Ecuador y países latinoamericanos es pionera en el análisis, reflexión, compromiso y desafío, cuyos resultados pueden ser útiles para laicos, seglares comprometidos, religiosos y pastores de todo credo religioso; por lo tanto, pueden ser abordados desde el campo teológico, filosófico y en otras disciplinas.

\section{Bibliografía}

Campos, L. (2013). La Indiferencia Religiosa y el Estado Laico en México. [Mensaje de Blog]. Disponible en: https://lauracampos.wordpress.com/indiferenciareligiosa/

Castilla, C. (2015). Del desinterés al entusiasmo. El fenómeno religioso en la investigación etnográfica española. Revista Gazeta de antropología, 31, (2), 1 14. Disponible en: http://hdl.handle.net/10481/36829

Concilio Vaticano II. (1995). Gaudium et Spes. Santa Fe de Bogotá.

Fabra, A. (2015). La indiferencia religiosa y la sociedad contemporánea. [Mensaje de Blog]. Disponible en: http://www.religionenlibertad.com/la-indiferenciareligiosa-contemporanea-44611.htm

Jans, S. (1989). La concepción religiosa de Dios. Recuperado el 7 de julio del 2021 http://www.oocities.org/masonchile/conceprelig.htm

López, M. (2015). Proponer la fe cristiana en una cultura de increencia e indiferencia religiosa. Pontificia universidad Javeriana, Facultad de Teología. Bogotá D.C. Disponible en: http://repository.javeriana.edu.co/bitstream/10554/16996/1/LopezMoraMilt onDavid2015.pdf

Ortiz, A. J. (1993). Los caminos de la increencia (IV): la marea de la indiferencia religiosa. Proyección: Teología y mundo actual, (169), 105-118. Recuperado de: file:///C:/Users/DELL/AppData/Local/Temp/DialnetLosCaminosDeLalncreencialV-7322190-1.pdf 
Pascual, F. (2014). El fenómeno religioso. Recuperado el 28 de Mayo del 2015 de https://es.catholic.net/op/articulos/21521/cat/671/el-fenomenoreligioso.html

Patiño, M. (2007). Informe fundación encuentro. España. Recuperado el 3 de Diciembre del 2014 de http://www.fundencuentro.org/informe_espana/presentaciones.php?id=IE14

Pedace, R. (2008) Pastores y referentes opinan sobre inédita encuesta religiosa en la Argentina. Pulso Cristiano [en línea]. Disponible en: http://www.pulsocristiano.com.ar/newss/entrevista_pulso118b.htm

Peña, V. (s.f.). Meditaciones acerca de la filosofía primera, en las cuales se demuestra la existencia de Dios, así como la distinción real entre el alma y el cuerpo del hombre. Recuperado el 27 de junio del 2016 de http://www.mercaba.org/Filosofia/Descartes/med_met_alfaguara.PDF

Real Academia Española. (2001). Diccionario de la lengua española (22. Ed.). Consultado en http://lema.rae.es/drae/?val=agnosticismo

Rincón Rueda, A. (2018) La religión y la formación de la civilidad. Sophia [online]. Recuperado de: http://scielo.senescyt.gob.ec/scielo.php?script=sci_abstract\&pid=S1390$86262018000100171 \& \operatorname{lng}=\mathrm{pt} \& \mathrm{nrm}=$ iso\&tlng=pt

Ruiz, Antonio, C.M. (2016). El desafío de la indiferencia religiosa: planteamientos desde la credibilidad de la Iglesia y la Cristología actual. [Mensaje de Blog]. Recuperado de: http://vicencianos.org/el-desafio-de-la-indiferenciareligiosa-planteamientos-desde-la-credibilidad-de-la-iglesia-y-lacristologia-actual/

Serrano, J. P. G., González-Carvajal, L., \& Velasco, J. M. (2011). La indiferencia religiosa en la sociedad postmoderna Pág. 11-13. Recuperado de: https://espiritualidad.marianistas.org/wpcontent/uploads/2014/08/textos_de_hoy_250_-anos_despues.pdf

Velasco, J. Martín. (1988). Increencia y evangelización. Del diálogo al testimonio (2. ${ }^{\text {a. }}$ edición). Editorial Sal Terrae Santander, pág. 31-50. Disponible en: http://www.libroesoterico.com/biblioteca/Teologia/Velasco\%20Juan\%20Mar 
tin\%20Increencia\%20Y\%20Evangelizacion\%20Del\%20Dialogo\%20Al\%20Testi monio\%20Afr\%20Presencia\%20Teologica.pdf

\section{Anexo}

A continuación, presentamos el cuestionario aplicado:

1. ¿En algún momento de su vida se ha cuestionado la existencia de Dios?

$$
\mathrm{SI}(\mathrm{NO}(\mathrm{)}
$$

2. ¿Cree que es necesario profesar una religión para creer en Dios

$$
\mathrm{SI}(\mathrm{NO} \quad \mathrm{NO}
$$

3. ¿Se identifica con alguna ideología religiosa?

Católico ( ) Evangélico ( ) Testigos de Jehová ( ) Mormones ( ) Ninguno ( )

4. Entre 0 a 4 marque dentro del cuadro, ¿con qué frecuencia asiste al lugar de culto?

$\square 0=$ Nunca $\square 1=$ Casi nunca $\square=$ A veces $\square 3=$ Casi siempre $\square$ 4= Siempre

5. ¿Piensa que los principios morales de la religión han pasado de moda?

$$
\mathrm{SI} \quad \mathrm{NO}(\quad)
$$

6. Entre 0 a 3, marque dentro del cuadro ¿con qué frecuencia cree que es importante en el núcleo familiar una educación espiritual?

$\square 0$ = Nada importante $\quad \square 1=$ Poco importante $\quad \square 2=$ Importante $\square$ 3= Muy importante

7. ¿Considera que la descomposición familiar es fruto de la carencia de valores religiosos?

$$
\mathrm{SI}(\quad) \quad \mathrm{NO}(\quad)
$$

8. ¿Piensa que los valores morales ayudarían a nuestra sociedad?

$$
\mathrm{SI}(\quad) \quad \mathrm{NO}(\quad)
$$

9. ¿Cree que el materialismo ha afectado la identidad religiosa de las personas?

$$
\mathrm{SI}(\quad \mathrm{NO}(\quad)
$$


10. Marque con una $X$ la respuesta que Usted considere correcta ¿A qué atribuye que un joven universitario manifieste indiferencia hacia la religión?

Familia de diferente religión（ ） Ejemplo negativo de líderes religiosos ( ) Influencia negativa del internet ( ) Desintegración familiar ( )

11. ¿Cuáles son las motivaciones que le llevan a participar en las actividades religiosas?

Curiosidad ( ) Obligación( ) Compromiso( ) Convicción( )

12. Entre 0 a 4, marque dentro del cuadro ¿Qué tiempo dedica Usted al uso de medios de comunicación?

$\square \mathrm{a}=$ Menos de 1 hra $\square$ 1b= de 1 a 3 hrs $\square$ c= $\quad \square$ a 5 hrs $\square$ d= más de 5 hrs

13. Marque con una $X$ la respuesta que crees necesario ¿Qué tipo de medio de comunicación utiliza con frecuencia?

Internet ( ) Radio ( ) Televisión( ) Celular ( ) 